\title{
Granular Herbicide Applicator for Brush Control
}

T. O. FLYNT, R. W. BOVEY, R. E. MEYER, T. E. RILEY, AND J. R. BAUR

Highlight: An applicator was constructed and mounted on a tractor to accurately apply granular or pelleted herbicides in continuous narrow bands at various spacings to soils supporting infestations of brush. The metering mechanism consisted of a rotating disc suspended directly over an opening in the bottom of a hopper. Uniformity of granule output could be calibrated within $<5 \%$ error.

The application of granular herbicides and other agricultural chemicals is a common practice in many cropping systems. Numerous spray devices have been de-

Authors are agricultural research technician, research agronomist, plant physiologist, agricultural research technician, and plant physiologist, Agricultural Research Service, U.S. Department of Agriculture, Department of Range Science, Texas A\&M University, College Station 77843

Manuscript received December 5, 1975. veloped for dispersal of liquid herbicide formulations, but less equipment has been developed for accurate application of granular materials.

Lovely et al. (1966) studied various metering machines for application of granulated insecticides for European corn borer control. Their data indicated that successful metering mechanisms included an augertype fertilizer distributor, fluted-feed grass seeder, a reciprocating-chain type grass seeder, a fluted-shaft granular applicator, and a reciprocating-rope seeder. Danielsen and Chambers (1957) developed an experimental field distributor for granular herbicides which employed an auger enclosed in a slotted tube as a metering device in the bottom of the hopper.

Wooten and McWhorter (1961) described a subsurface applicator to apply dusts and granules in bands. Air pressure was used to force the dusts and granules into the soil through a boom attached to a horizontal blade pulled by a tractor. Bingham (1964) modified a grass seed attachment to a grain drill to apply granular herbicides. The fluted-feed cup metering mechanism gave positive and precise metering, low physical breakdown of granules and a discharge rate directly proportional to the speed and amount of flute exposed to the granular material. More recently, Anderson (1974) developed an applicator that used the principle of the cone seeder to obtain uniform distribution of granules. The device had the advantage that no calibration or adjustment was necessary when rates of application were varied or when different formulations of granules were used, providing plot size was held constant.

Previous research by Bovey et al. (1975) indicated that certain herbicides applied to the soil surface as sprays or granules in continuous bands 4 to $6 \mathrm{ft}$ apart were effective for brush control. Application of some soil 
active herbicides in bands as contrasted to broadcast application increased brush control and decreased injury to desirable forbs and grasses. Most applications of granular herbicides to experimental areas heretofore had been made by hand, making it difficult to treat large areas in dense, spiney brush with accuracy.

Our objective was to design tractormounted application equipment to apply granular herbicides accurately in continuous narrow bands spaced at various intervals in areas supporting woody vegetation.

\section{Equipment}

The granular applicator was constructed from the hopper of a discarded grass seeder (manufacturer unknown). The hopper was 12 inches wide, 17.5 inches long, and 12 inches deep (Fig. 1 A). At the bottom of the hopper, two 0.75 -inch $^{2}$ openings diagonal to the direction of the shaft) were spaced at 6 inches from either end. The bottom of the hopper was rounded to accommodate two 7-inch-diameter feeding discs supported on a 1.25-inch shaft. Feeder discs made from 0.026-inch metal were placed directly over the openings in the bottom of the hopper. A 0.188 -inch clearance was provided between the disc and hopper opening. The fecder discs were bent about 0.75 -inch off center on either side and had four 1-inch holes spaced equidistant near the perimeter to provide uniform feeding and distribution of granules through the hopper openings. Two 0.5 - by 1.0 - by 2.5 -inch bars welded on opposite sides of the shaft between the feeder discs were slanted toward the feeder discs. The bars served to distribute granules or seeds toward the feeder discs and hopper openings during operation.

The unit is powered by a 2-hp Briggs and Stratton (Fig. 1 B) air-cooled engine connected to a 10:1 ratio gear reducer box (Type UF or M, size 113A, Gear USA, Boston, Mass.). ${ }^{1}$ A 2-inch sprocket wheel from the gear reducer box drives a 10 -inch sprocket wheel on the feeder mechanism shaft by a No. 40 chain. The feeder shaft turns at $50 \mathrm{rpm}$.

The motor and gear reducer box is mounted on a 10 - by 18 -inch plate of $0.375-$ inch metal. The entire apparatus is supported by a 1.5-inch pipe frame welded beneath the motor and hopper (Fig. $1 \mathrm{C}$ ).

The hopper opening is adjusted to the desired aperture by a 1.5 -inch ${ }^{2}$ sliding metal plate or gate at the underside of the hopper (Fig. 1 C). the two gates can be opened in unison or separately by simple mechanical adjustment. The gates can be opened or closed by a lever in reach of the tractor operator.

Mention of a trademark name or a proprietary product docs not constitute a guarantee or warranty of the product by the U.S. Department of Agriculture or Texas A\&M University, and does not imply their approval to the exclusion of other products that may also be suitable.
During operation, granules drop from the hopper opening into a pipe reducer (3.5- to 1 -inch), which acts as a funnel. A 1 -inch hose or tube connected at the bottom of the pipe reducer by a 1 -inch pipe nipple directs the granules or pellets to the desired point of distribution (Fig. 1 D).

\section{Performance}

Spherical granules (approximately 0.05 inch diameter) and extruded pellets up to 0.15 -inch diameter were applied at 10 or $20 \%$ active ingredient of herbicide on replicated plots at rates of 0.5 to $8 \mathrm{lb} /$ acre. Granular herbicides included bromacil (5bromo-3-sec-butyl-6-methyluracil), karbutilate [tert-butylcarbamic acid ester with 3-(m-hydroxyphenyl) - 1,1-dimethylurea], picloram (4-amino-3,5,6-trichloropicolinic acid), and tebuthiuron [1-(5-tert-butyl-1,3, 4-thiodiazol-2-yl) - 1,3-dimethylurea] on areas supporting stands of honey mesquite [Prosopis juliflora (Swartz) DC. var. glandulosa (Torr.) Cockerell], huisache (Acacia farnesiana (L.) Willd.), whitebrush (Aloysia lycioides Cham.), live oak (Quercus virginiana Mill.) and post oak (Quercus stellata Wangenh.), and yaupon (Ilex vomitoria Ait.).

The granular applicator was mounted on a 1010 John Deere (Fig. 1 D) or a D7Caterpillar $^{1}$ (Fig. $1 \mathrm{E}$ ). The applicator was placed on the tractor in such a way as to protect it from damage by passing or falling trees. In large trees and brush the applicator was mounted over the engine of the D7Caterpillar, and granules were dispersed directly in front of the track as the tractor progressed (Fig. 1 E). This type of application was desirable in that the granules were usually buried in the soil from the weight and movement of the tractor. However, on wet soils, granules must be dropped behind the tracks to prevent them from adhering to the moist soil on the tracks of the tractor (Fig. 1 D).

When band spacings wider than $6 \mathrm{ft}$ were applied, one of the openings on the applicator was closed, so that only one dispersal unit was used. This allowed investigation of forage and brush response to herbicides applied in band spacings of 10,15 , or $20 \mathrm{ft}$.

Calibration of the granular applicator consisted of adjusting the flow rate to give the desired rate per acre, in conjunction with tractor speed and band spacing. For example, if the tractor speed is $100 \mathrm{ft}$ per 30 seconds, actual area covered equals 0.0275 of an acre $\left(100 \times 12 \mathrm{ft}=1,200 \mathrm{ft}^{2}\right)$ when 2 bands are placed $6 \mathrm{ft}$ apart. If 2 $\mathrm{lb} /$ acre of $10 \%$ active herbicide is required, then $20 \mathrm{lb}$ or $9,080 \mathrm{~g} /$ acre of actual material is needed. Flow rate for 30 seconds would be $0.0275 \times 9,080$ or 250 grams.

We used the applicator extensively in experimental application of various granular herbicides to several brush types and locations in Texas. No problems were encountered with mechanical failure or appli- cation of different sizes and types of granular herbicides. Difficulties were encountered in high winds ( 15 to $25 \mathrm{mph}$ ), when the granules were blown away before falling into the 3.5-inch funnels below the hopper. The situation was corrected by blocking the airflow under the hopper. Applications of the granules can be made under windy conditions, since they are released in close proximity to the soil surface.

Preliminary data indicate that on most brush species band applications of the same herbicide and rate per acre spaced on 6- to $10-\mathrm{ft}$ centers are equal to or superior to broadcast applications or spacings of bands greater than on 10 - $\mathrm{ft}$ centers.

Advantages of applying granular herbicides in continuous bands for brush control include:

1. No mixing or special preparation required (commercial herbicides available).

2. Can be applied throughout most of the year.

3. Application method is accurate.

4. Can be used next to areas with sensitive vegetation, where foliar sprays may cause damage from drift.

5. Can be used in almost all types of brush and terrain.

6. Can be used with other brush control methods including chopping, chaining, and mowing or fertilizer and seeding operations.

7. With a large hopper, many acres can be treated without refilling.

8. Causes less damage to desirable forages than does broadcast application.

Disadvantages include the following:

1. Operation is slow compared to airplane application.

2. Granular herbicides are presently more expensive to use than foliar sprays. 3. Usage is limited where soils are wet and unstable.

\section{Literature Cited}

Anderson, R. N. 1974. A small-plot granular herbicide applicator that requires no calibration. Weed Sci. 22:193-197.

Bigham, S. W. 1964. Flute-feed applicator for granular herbicides. Weeds 12:58-59.

Bovey, R. W., T. O. Flynt, R. E. Meyer, J. R. Baur, and T. E. Riley. 1976. Subsurface herbicide applicator for brush control. J. Range Manage. 29:338-341.

Danielson, L. L., and P. R. Chambers. 1957. A field distributor for granular herbicide trials. Weeds 5:108-111.

Iovely, W. G., H. C. Cox, and T. A. Brindley. 1956. Application equipment for granulated insecticides. J. Econ. Entomol. 49:839-846.

Wooten, O. B., and C. G. McWhorter. 1961. Equipment for the subsurface application of solid herbicides. Weeds 9:658-659. 